\title{
Renal Clearance for Dose Interval Normalized by Weight
}

National Cancer Institute

\section{Source}

National Cancer Institute. Renal Clearance for Dose Interval Normalized by Weight. NCI Thesaurus. Code C122337.

The clearance of a substance from the blood by the kidneys, calculated using the area under the curve over the dosing interval, divided by the weight. 